\title{
Dysgerminoma of the ovary in a patient with triple-X syndrome (47, XXX) and Marfanoid habitus features
}

\author{
Karolina Moskwinska®D, Marcin Sniadecki(D), Dariusz Wydra® \\ Department of Gynecology, Gynecologic Oncology and Gynecologic Endocrinology, Medical University of Gdansk, Poland
}

Key words: dysgerminoma; triple-X syndrome; Shprintzen-Goldberg syndrome; Marfan syndrome

Ginekologia Polska 2021; 92, 6: 466-467

\section{INTRODUCTION}

Dysgerminoma is a malignant ovarian tumor beginning in premeiotic germ cells, with clinically aggressive behavior and good prognosis. Triple- $X$ syndrome is characterized by an extra $\mathrm{X}$ chromosome due to a random error during cell division in sperm or egg formation and is not typically an inherited condition. Premature ovarian failure or ovarian abnormalities are sometimes found coincidentally. Associations between triple $X$ syndrome and dysgerminoma have never been investigated.

\section{CASE REPORT}

A 22-year-old woman with Marfanoid habitus and an ovarian dysgerminoma (Fig.1) was admitted to the Department of Gynecology. The patient's medical history showed borderline intellectual disability and clinical suspicion of Marfan syndrome (MFS) (Fig. 2)

Surgical treatment was performed, and post-surgery, four cycles of bleomycin, etoposide, cisplatin (BEP) chemotherapy. She is alive and well with no signs of recurrence 10 years after the completion of treatment.

\section{MATERIAL AND METHODS}

Cytogenetic studies were performed using conventional GTG-banding of lymphocyte metaphase chromosomes at a 550-band level. DNA was isolated from the peripheral blood leukocytes of the patient and of nine anonymous healthy female volunteers (reference control DNA). Array Comparative Genomic Hybridization ( $\mathrm{aCGH}$ ) analysis was performed. Genomic imbalances identified were verified in the Database of Genomic Variants (DGV; http://projects.tcag.ca/variation; last accessed December 2020). We searched ECARUCA [1], Decipher [2] and Medline/OMIM [3] for instances of patients with constitutional chromosomal aberrations at chromosome $4 \mathrm{q} 26$.

\section{RESULTS}

The patient was diagnosed with triple-X syndrome by karyotyping: 47, XXX. Further aCGH analysis confirmed the chromosome analysis and identified interstitial deletion of about $1.1 \mathrm{Mb}$ at chromosome $4 \mathrm{q} 26$.

Following the revised Ghent Marfan Syndrome Diagnostic Criteria (2010) [4], the patient having only skeletal features but no signs of other organ systems' involvement, and a negative mutation evaluation of the FBN1 gene, diagnosis excluded MFS. Differ-

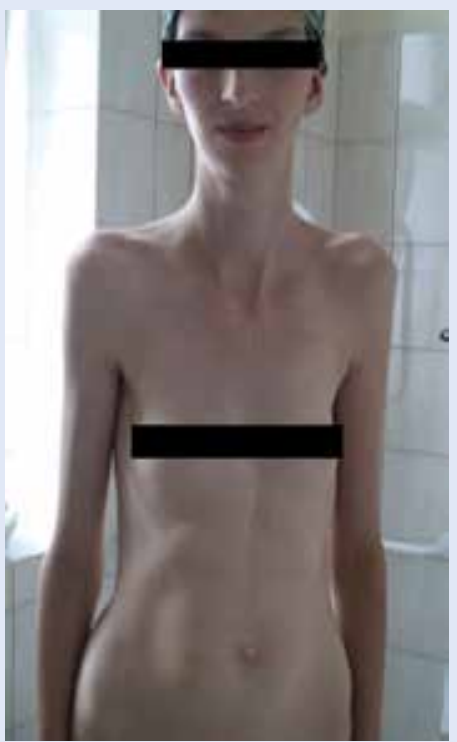

Figure 2. Clinical features of Marfanoid habitus (dolichocephaly, micrognathia, pectus carinatum, elongated extremities) ential diagnosis identified Shprintzen-Goldberg syndrome [5] as the most likely alternative diagnosis.

Corresponding author:

Karolina Moskwinska

Department of Gynecology, Gynecologic Oncology and Gynecologic Endocrinology, Medical University of Gdansk, Poland e-mail:k.moskwinska@gmail.com

This article is available in open access under Creative Common Attribution-Non-Commercial-No Derivatives 4.0 International (CC BY-NC-ND 4.0) license, allowing to download articles and share them with others as long as they credit the authors and the publisher, but without permission to change them in any way or use them commercially. 


\section{DISCUSSION}

Genetic studies confirmed diagnosis of the triple-X syndrome and revealed a novel interstitial deletion at chromosome 4q26. The deletion spanned $1.1 \mathrm{Mb}$, comprised of one gene protein coding: translocation associated membrane protein 1 like 1 (TRAM1L1) of unknown function.

The OMIM database provided no information on this gene mutation [3], nor is such reported in the Developmental Disorders Genotype-Phenotype Database [2]. The decipher haploinsufficiency score ( $\mathrm{Hl}$ index) was estimated as $85 \%$, and accordingly, the gene is unlikely to exhibit haploinsufficiency [2]. The adjacent genomic regions were not found to be enriched in low copy repeat sequences or segmental duplications, nor possessing significant enhancer/silencer or promotor-associated histone marks (www.genome.ucsc. edu). Therefore, it seems unlikely that the novel $4 q 26$ deletion was responsible for the clinical features observed in the patient.

Among individuals with chromosome aberrations, a higher risk of germinal tumors has been found in cases of $45, X / 46, X Y$ mosaicism, resulting in active oncological prophylaxis in these patients. Associations between triple- $X$ syndrome and ovarian tumors have been rarely documented. Ovarian tumors have not been clinically linked to Shprintzen-Goldberg syndrome so far. However, further research on the cooccurrence of germ cell tumors and chromosomal abnormalities is necessary to identify risk factors of these relatively rare neoplasms.

\section{Acknowledgements}

This study used data generated by the DECIPHER community. A list of centres contributing to the data generation is available from https://decipher.sanger.ac.uk/about/stats and via email from decipher@sanger.ac.uk. DECIPHER project funding was provided by Wellcome.

The authors would like to thank Beata Lipska-Ziętkiewicz and Magdalena Koczkowska (Department of Biology and Medical Genetics, Medical University of Gdańsk) for their help in writing the manuscript.

\section{Conflicts of interest}

The authors declare no conflict of interest.

\section{REFERENCES}

1. Feenstra I, Fang J, Koolen DA, et al. European Cytogeneticists Association Register of Unbalanced Chromosome Aberrations (ECARUCA); an online database for rare chromosome abnormalities. Eur J Med Genet. 2006; 49(4): 279-291, doi: 10.1016/j.ejmg.2005.10.131, indexed in Pubmed: 16829349.

2. Firth HV, Richards SM, Bevan AP, et al. DECIPHER: Database of Chromosomal Imbalance and Phenotype in Humans Using Ensembl Resources. Am J Hum Genet. 2009; 84(4): 524-533, doi: 10.1016/j.ajhg.2009.03.010, indexed in Pubmed: 19344873.

3. http://www.ncbi.nlm.nih.gov/omim/.

4. Loeys BL, Dietz HC, Braverman AC, et al. The revised Ghent nosology for the Marfan syndrome. J Med Genet. 2010; 47(7): 476-485, doi: 10.1136/jmg.2009.072785, indexed in Pubmed: 20591885.

5. Shprintzen RJ, Goldberg RB. A recurrent pattern syndrome of craniosynostosis associated with arachnodactyly and abdominal hernias. J Craniofac Genet Dev Biol. 1982; 2(1): 65-74, indexed in Pubmed: 6182156. 